\title{
Levantamento de feições estruturais lineares a partir de sensoriamento remoto - uma contribuição para o mapeamento geotécnico na Serra de Baturité, Ceará Survey of linear structural features from remote sensing - a contribution to the geotechnical mapping in Baturité Mountain, Ceará
}

\author{
Clístenes Teixeira Batista1, César Ulisses Vieira Veríssimo², Wagner da Silva Amaral ${ }^{3}$ \\ ${ }^{1}$ Departamento de Geografia, Centro de Ensino Superior do Seridó, Universidade Federal do Rio Grande do Norte - UFRN, \\ Rua Joaquim Gregório s/n, Bairro Penedo, CEP 59300-000, Caicó, RN, BR (batista.ct@hotmail.com) \\ ${ }^{2}$ Departamento de Geologia, Universidade Federal do Ceará - UFC, Fortaleza, CE, BR (verisssimo@ufc.br) \\ ${ }^{3}$ Instituto de Geociências, Universidade Estadual de Campinas - UNICAMP, Campinas, SP, BR (wamaral@ige.unicamp.br)
}

Recebido em 23 de setembro de 2013; aceito em 28 de março de 2014

\begin{abstract}
Resumo
O uso de técnicas de processamento digital de imagens de sensores remotos permite aplicações de grande importância para as geociências. Um dos campos de possível aplicação desses recursos é o mapeamento geotécnico. Técnicas de filtragens em imagens ópticas e de radar ressaltam estruturas lineares naturais que podem ser interpretadas como falhas, fraturas, drenagens, cristas, fundos de vale e foliações. Com o levantamento desses dados, combinados com os trabalhos de campo, o mapeamento geotécnico ganha em precisão e agilidade. A grande incidência de eventos de instabilidade de encostas ocorridas recentemente em algumas regiões do Brasil, notadamente na região Sudeste, tem atraído o interesse de pesquisadores das áreas de engenharia e geociências no desenvolvimento de estudos que abordem essa temática. Foi medida a direção em azimute e o comprimento em metros dos vetores correspondentes aos lineamentos, para posterior geração de um diagrama de rosetas e visualização do trend regional dessas estruturas e elaboração de mapa de densidade de lineamentos. A importância da aplicação de filtros de frequência espectrais consiste, portanto, em quantificar e qualificar essas estruturas geológicas e geomorfológicas, que estão entre os componentes principais de condicionantes de movimentos de massa e erosão.
\end{abstract}

Palavras-chave: Geoprocessamento; Geotécnica; Movimentos de massa.

\begin{abstract}
The use of techniques of digital image processing remote sensing allows applications of great importance for the geosciences. One of the possible fields of application of these resources is the geotechnical mapping. Filtering techniques for radar and optical images emphasize natural linear structures that can be interpreted as fractures, drainages, ridges, valley bottoms and foliation. With the lifting of these data, combined with field work, the geotechnical mapping gains in precision and agility. The high incidence of slope instability events recently occurred in some parts of Brazil, especially in the Southeast, has attracted the interest of researchers in engineering and geoscience areas in the preparation of monographs, dissertations, theses and academic articles that address this issue. For subsequent generation of a diagram rosettes and visualization of regional trend of the structures and preparation of lineament density map, the vectors corresponding to the guidelines direction were measured in azimuth, and the length was measured in meters. The importance of applying frequency spectrum filters is therefore to quantify and qualify these geological and geomorphological structures, which are among the main components of conditions of mass movements and erosion.
\end{abstract}

Keywords: Geoprocessing; Geotechnical; Mass movements. 


\section{INTRODUÇÃO}

A Serra de Baturité, no Ceará, embora não apresente taxas tão altas de densidade demográfica e de pluviosidade quanto as regiões serranas do Rio de Janeiro e de São Paulo, é uma região onde é mais notória a presença de áreas de instabilidade geotécnica e que apresenta a maior predisposição à ocorrência de movimentos de massa e instabilidade de taludes. Na Serra de Baturité, a pluviosidade atinge o máximo de $1.500 \mathrm{~mm} /$ ano e a densidade demográfica dos municípios da região é da ordem de $100 \mathrm{hab} . / \mathrm{km}^{2}$, enquanto que na Serra do Mar, no Estado de São Paulo, e na região serrana do Rio de Janeiro, os índices de pluviosidade chegam a $5.000 \mathrm{~mm} /$ ano e a densidade demográfica é superior a 800 hab. $/ \mathrm{km}^{2}$ (Bastos, 2012).

Do ponto de vista mecânico, a instabilidade de um talude ou encosta ocorre quando as tensões cisalhantes mobilizadas se igualam à resistência ao cisalhamento, o que pode ocorrer pelo aumento das tensões cisalhantes ou pela redução da resistência ao cisalhamento (Gerscovich, 2009). Na área de estudo, essa instabilidade está associada principalmente à presença de rodovias e estradas e à ocupação de encostas nos núcleos urbanos e áreas rurais.

Os principais fatores geológicos que condicionam os movimentos de massa englobam a litologia e as estruturas. A composição mineralógica e a granulometria, bem como a textura, o grau de coesão e a presença de estruturas tais como xistosidade, foliação, estratificação, falhas e fraturas definem a permeabilização e a resistência ao intemperismo e, consequentemente, a suscetibilidade à erosão e à movimentação de blocos rochosos. Dependendo do ângulo de mergulho e da direção das foliações, falhas e fraturas em relação à orientação e ao caimento da vertente, uma grande variedade de tipos de ruptura de taludes e movimentos de massa podem ser potencializados. Dessa forma, o conhecimento do meio físico, que pode ser obtido a partir do processo de mapeamento onde o comportamento dos seus atributos é avaliado em conjunto, é indispensável na previsão de riscos geológicos. Com isso, pode-se definir critérios de suscetibilidade e adequabilidade do terreno às diferentes formas de uso e ocupação.

Atualmente, um dos instrumentos mais importantes nos estudos do meio físico é o sensoriamento remoto. Por meio de seus produtos e aplicações é possível obter informações fundamentais que subsidiam a avaliação dos componentes ambientais e ajudam na tomada de decisões. Nos estudos geotécnicos, o sensoriamento remoto pode contribuir no mapeamento geológico e no levantamento de feições lineares estruturais associadas a fraturas, falhas, zonas de cisalhamento, etc. Logo, seu estudo detalhado pode fornecer suporte para estudos geotécnicos que promovam a produção de cartas de suscetibilidade e de condições geotécnicas do terreno, estabelecendo critérios de uso e ocupação através da definição de limitações e potencialidades do mesmo.
Dessa forma, o objetivo deste trabalho é promover o levantamento de dados a partir de sensoriamento remoto, e com o tratamento dos mesmos elaborar uma série de produtos cartográficos de caráter orientador que, somado a outros fatores deflagradores de movimentos de massa, como litologia e declividade, possam servir de suporte a um zoneamento geotécnico.

\section{Localização da área de estudo e seu contexto geológico e geomorfológico}

As principais litologias da Serra de Baturité estão relacionadas à Unidade Independência, a intrusões graníticas, e a depósitos coluvio-eluviais e aluviais, os quais recobrem vertentes e fundos dos vales, respectivamente (CPRM, 2012).

A associação metassedimentar é dominada por rochas metapelítcas e/ou metapsamo-pelíticas representadas por paragnaisses e xistos com biotita e/ou muscovita e intercalações lenticulares de quartzitos, rochas calcissilicáticas e mármores, em parte com porções silicosas (Torres, 2004; Torres et al., 2006).

O domínio dos paragnaisses é caracterizado pela predominância de quartzitos micáceos, metacarbonatos calcíticos e/ou dolomíticos, rochas cálcio-silicáticas e metabásicas representadas por granada anfibolito, além de gnaisses graníticos cinzentos (CPRM, 2012).

Os mármores ocorrem, em sua maioria, como um alinhamento de corpos lenticulares calcítico-dolomíticos, brancos a cinza claros e de granulação média, por vezes contendo tremolita, diopsídio e quartzo. As rochas calcissilicáticas ocorrem também em forma lenticular exibindo estrutura gnáissica (Cavalcante et al., 2003; Torres, 2004).

Os quartzitos ocorrem próximos às bordas da Unidade Independência na forma de corpos lenticulares, sustentando as maiores elevações na área, e apresentam composição que varia de quartzitos feldspáticos a quartzitos relativamente puros e/ou calcíticos, esses últimos ocorrendo próximos a lentes de mármore (Figura 1).

De modo geral, a região de estudo foi afetada por movimentos deformacionais de natureza dúctil, que imprimiu nas rochas uma foliação tectono-metamórfica, determinando um bandamento composicional nos gnaisses e pronunciada xistosidade nos litotipos micáceos, além de dobras e outras estruturas típicas de deformação e metamorfismo em condições de médio grau (Silva, 2007).

As deformações incluem também, conjuntos de zonas de cisalhamento dúcteis transcorrentes com desenvolvimento de milonitos, principalmente quando separam termos orto de paraderivados. Estruturas rúpteis representadas por fraturas e falhas controlam grande parte das drenagens e a orientação de algumas serras (Torres, 2004).

Do ponto de vista geomorfológico, a Serra de Baturité, de acordo com Souza et al. (1979) e Souza (2000), está inserida 


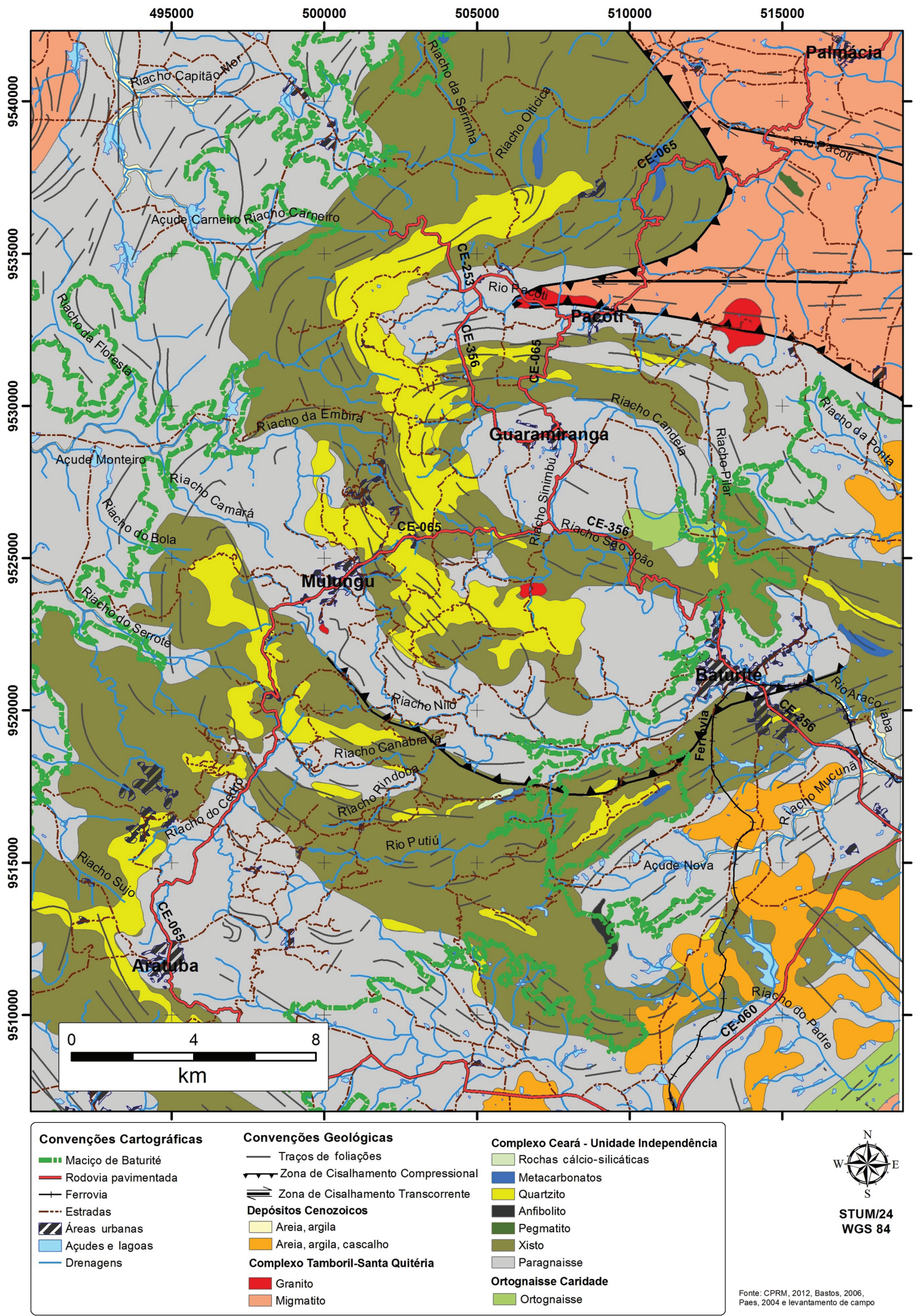

Figura 1. Geologia da região da Serra de Baturité (Modificado de CPRM, 2012). 
nos Escudos e Maciços Antigos do Ceará, que correspondem aos terrenos cristalinos pré-cambrianos, que formam os Maciços Residuais dos quais a referida serra faz parte, e à Depressão Sertaneja.

A região que constitui o objeto de pesquisa deste trabalho compõe uma paisagem de exceção do sertão semiárido cearense e apresenta características naturais bastante distintas de seu entorno semiárido.

A Serra de Baturité possui orientação predominante NNE-SSW, com níveis altimétricos que alcançam de 600 a $800 \mathrm{~m}$, em média (Figura 2). Excepcionalmente, alguns níveis de cristas superam a cota de $900 \mathrm{~m}$ e atingem até $1.114 \mathrm{~m}$, o caso o Pico Alto, no município de Pacoti (Souza e Oliveira, 2006). Trata-se de montanhas isoladas tendo como superfície de piso (piemont), superfícies aplainadas, conservadas entre interflúvios e vertentes bastante inclinadas. (Bétard et al., 2007).

O Maciço de Baturité apresenta um relevo montanhoso de altitude moderada ( 800 a $900 \mathrm{~m}$ em média), que se sobressai por vertentes abruptas e sinuosas em relação às vastas superfícies aplainadas que caracterizam o sertão, situadas entre 100 e 200 m (Bétard et al., 2007). Boa parte do Maciço de Baturité foi modelada no mesmo tipo de gnaisses que compõe as baixas superfícies de aplainamento adjacentes, porém a maior parte dos escarpamentos e cristas elevadas são controladas por litologias relacionadas a quartzitos, através dos quais o maciço ficou preservado da ação da erosão regressiva acentuada.

\section{MATERIAIS E MÉTODOS}

Para a elaboração do mapeamento das feições estruturais na Serra de Baturité, foram utilizadas imagens do satélite LANDSAT 7 ETM (Enhanced Thematic Mapper) de resolução de 30 metros, cena 217-063 de 22/04/2002, e imagens de radar interferométrico da missão SRTM (Shuttle Radar Topography Mission) da NASA (National Aeronautics and Space Administration), refinados pelo projeto TOPODATA do INPE (Instituto Nacional de Pesquisas Espaciais).

O LANDSAT 7 ETM trata-se de um sensor óptico, enquanto que o SRTM consiste em um sistema de radar interferométrico de abertura sintética (SAR - Synthetic Aperture Radar). A sinergia entre dados ópticos e de radar em trabalhos de avaliação e monitoramento dos elementos ambientais, incluindo os trabalhos de mapeamento geotécnico, produzem resultados animadores e oferecem contribuições significativas para técnicos, pesquisadores e gestores públicos no que diz respeito ao planejamento e à tomada de decisões.

É possível aproveitar os fatores positivos de cada sistema na elaboração de produtos com maior quantidade de informações, pois os dados por eles registrados apresentam naturezas distintas e complementares. Logo, seu uso combinado pode ser altamente favorável, pois as imagens de SAR tendem a enfatizar a informação espacial (estruturas e texturas), enquanto que as imagens ópticas realçam a informação espectral (Chaves et al., 2003).

Destaca-se a importância da técnica de filtragem de frequências espectrais para os estudos geológicos e geotécnicos, que pode ser realizada tanto em produtos ópticos como de radar. Essa técnica consiste em realçar estruturas de baixa, média ou alta frequência nas imagens de sensoriamento remoto. As feições de alta frequência são caracterizadas por uma brusca variação dos níveis de cinza (DNs) da imagem, como os contatos litológicos, as redes de drenagem e estruturas geológicas como falhas e fraturas.

A aplicação de diferentes técnicas de filtragens utilizadas neste trabalho permitiu a identificação de feições lineares, como zonas de cisalhamento, falhas e fraturas, traços de foliação bem como redes de drenagem e divisores topográficos. Tais filtros atribuem valores de nível de cinza para os pixels da cena original em relação a uma média ponderada dos pixels vizinhos no realce de bordas em direções pré-definidas (Klein, 1998).

Foi medida a direção em azimute e o comprimento em metros dos vetores correspondentes aos lineamentos, para posterior geração de um diagrama de rosetas e visualização do trend regional dessas estruturas e elaboração de mapa de densidade de lineamentos. As estruturas lineares foram obtidas a partir da aplicação de filtros direcionais na imagem SRTM e de filtros passa-altas (high-pass) na imagem LANDSAT do Maciço de Baturité.

Foram aplicados filtros direcionais do tipo Kernel 5 X 5 em diferentes azimutes $\left(0^{\circ}, 45^{\circ}, 90^{\circ}, 135^{\circ}, 180^{\circ}, 225^{\circ}, 270^{\circ}\right.$, $315^{\circ}$ ) com o intuito de destacar os lineamentos estruturais de diferentes direções que ocorrem na região e filtros high-pass Kernel $3 \times 3$ na banda 04 da cena LANDSAT. Isso porque os filtros direcionais promovem o ressalto das estruturas lineares que se encontram em direção paralela à direção do filtro e a banda 04 do sensor LANDSAT apresenta sensibilidade à morfologia do terreno e serve para a análise e mapeamento de feições geológicas e estruturais. As imagens outputs foram salvas em formato GeoTiff e sobre elas vetorizados os lineamentos estruturais em formato shapefile (shp.).

A importância da aplicação de filtros de frequência espectrais consiste, portanto, em quantificar e qualificar as estruturas geológicas e geomorfológicas, que estão entre os componentes principais de condicionantes de movimentos de massa e erosão.

\section{RESULTADOS}

A partir da interpretação das imagens filtradas SRTM e Landsat foi possível extrair um total de 727 lineamentos na área de estudo, sendo a maioria deles de direção NE-SW, 


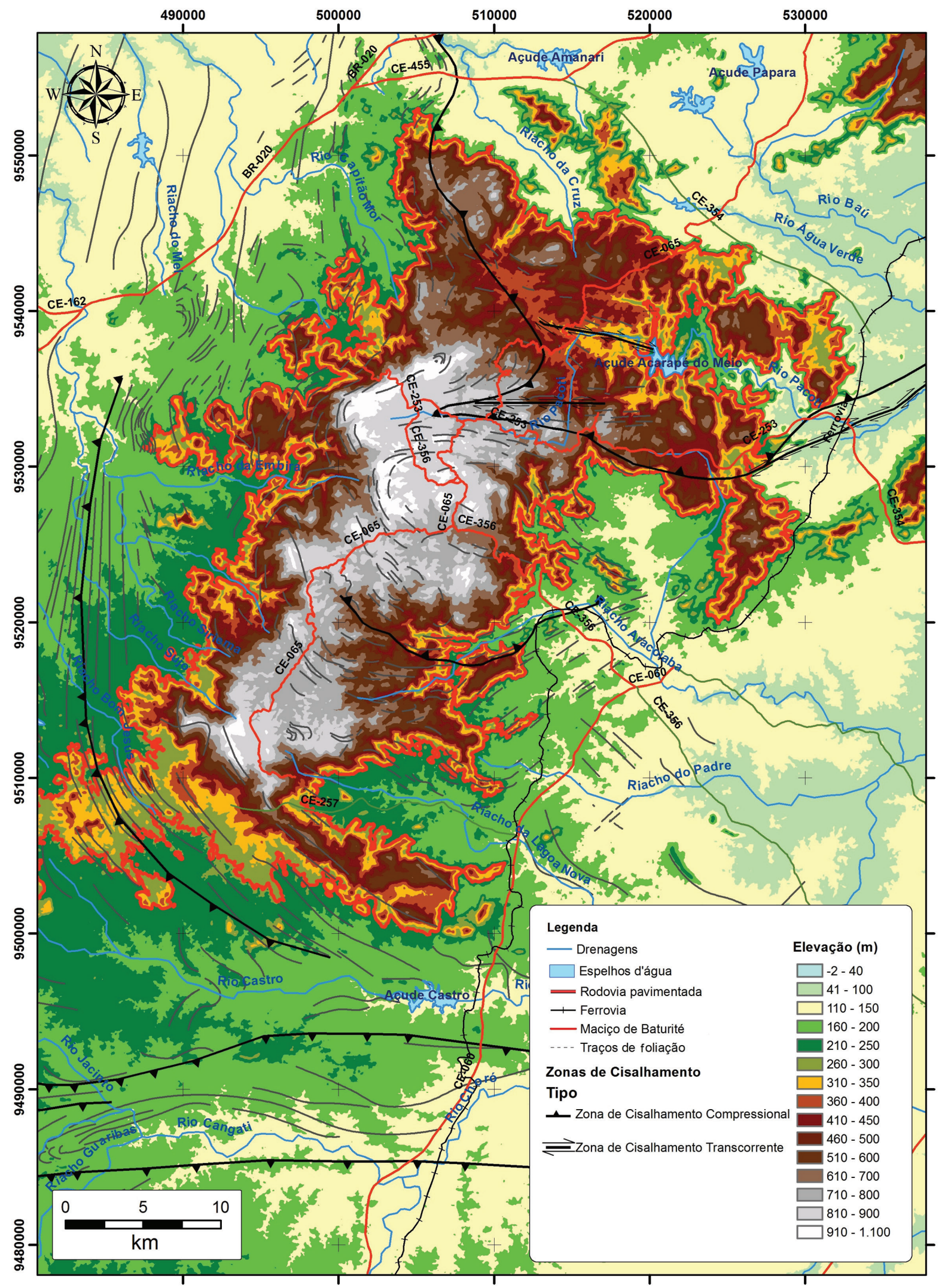

Figura 2. Visão geral do relevo e altimetria da Serra de Baturité. 
conforme mostra a Tabela 1. Esses lineamentos possuem um comprimento médio de aproximadamente $1.400 \mathrm{~m}$, sendo os maiores os de direção $\mathrm{N}-\mathrm{S}$, embora sejam justamente esses os que apresentam menor população de lineamentos entre as quatro classes de direções adotadas.

A análise das direções dos lineamentos permitiu a geração do diagrama de rosetas (Figura 3), onde se vê o claro predomínio das estruturas de sentido NE-SW, seguido dos lineamentos no sentido E-W. A determinação das direções dos mesmos foi atribuída segundo um diagrama de rosetas com intervalos definidos arbitrariamente conforme mostra a Figura 4, onde foi adotado um intervalo de $20^{\circ}$ para as direções N-S e E-W e de $70^{\circ}$ para as direções NE-SW e NW-SE.

A definição diferenciada de intervalos com ângulos menores para as direções $\mathrm{N}-\mathrm{S}$ e E-W tem como intuito salientar que as descontinuidades classificadas nessas direções sejam discriminadas mais apuradamente, enfatizando sua ocorrência em relação às descontinuidades NW-SE e $\mathrm{NE}-\mathrm{SW}$, que são mais frequentes.

Tabela 1. Números gerais dos lineamentos obtidos.

\begin{tabular}{lcc}
\hline Classes & População & Comprimento médio $(\mathrm{m})$ \\
\hline $\mathrm{N}-\mathrm{S}$ & 54 & $1.692,35$ \\
$\mathrm{E}-\mathrm{W}$ & 188 & $1.261,07$ \\
$\mathrm{NE}-\mathrm{SW}$ & 283 & $1.339,24$ \\
NW-SE & 202 & $1.348,28$ \\
\hline
\end{tabular}

Total de lineações $=727$.

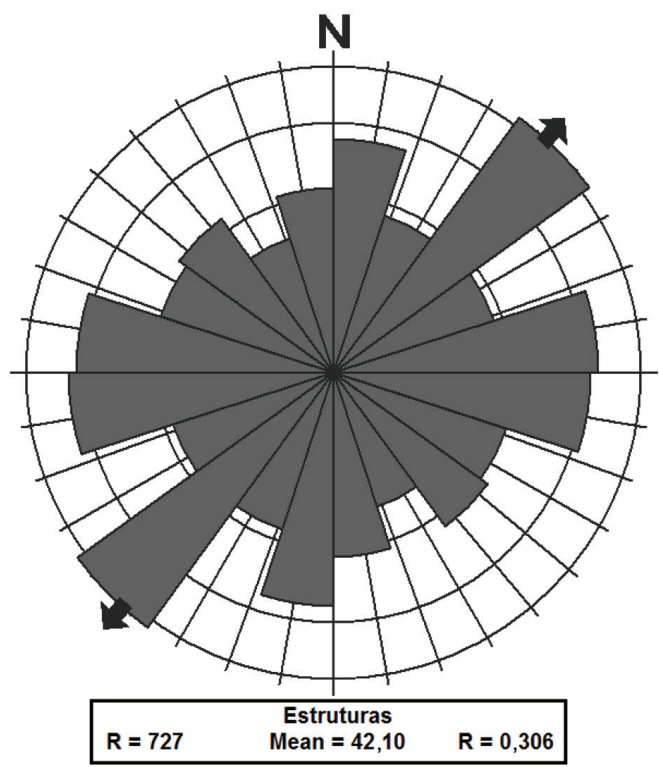

Figura 3. Diagrama de rosetas dos lineamentos da área de estudo.
Dessa forma, as famílias de descontinuidades orientadas entre $\mathrm{N} 10 \mathrm{~W}$ e $\mathrm{N} 10 \mathrm{E}\left(\mathrm{Az} 350^{\circ}\right.$ a $\left.10^{\circ}\right)$ são parte integrante da família N-S, e as orientadas N80E e S80E (Az $80^{\circ}$ a $\left.100^{\circ}\right)$ parte da família $\mathrm{E}-\mathrm{W}$. Os intervalos restantes, entre N11E e N79E $\left(\mathrm{Az} 11^{\circ}\right.$ a $\left.79^{\circ}\right)$ e N11W e S79W (Az 281 a $\left.349^{\circ}\right)$ foram considerados, respectivamente, como parte das famílias NE-SW e NW-SE.

A Figura 5 mostra os resultados dos filtros direcionais e high-pass aplicados nas imagens SRTM e Landsat da área de estudo. Nota-se as diferenças de contornos lineares entre as mesmas, o que permitiu a vetorização das descontinuidades que foram posteriormente agrupadas nas classes acima mencionadas.

\section{Mapa de direção de lineamentos}

Após a aplicação dos procedimentos anteriormente mencionados, o primeiro resultado obtido foi o mapa de direção de lineamento (Figura 6), onde se observa os lineamentos distribuídos nas quatro classes anteriormente mencionadas. (N-S, E-W, NE-SW, NW-SE).

\section{Mapas de densidade de lineamentos}

Foram elaborados também, como subprodutos da análise do mapa de lineamentos estruturais, os mapas de densidade de lineamentos (população $/ \mathrm{km}^{2}$ e comprimento em $\mathrm{km} / \mathrm{km}^{2}$ ). O primeiro mostra o número de lineamentos por determinada unidade de área e o segundo é o resultado do cálculo da densidade de cada forma linear por pixel no

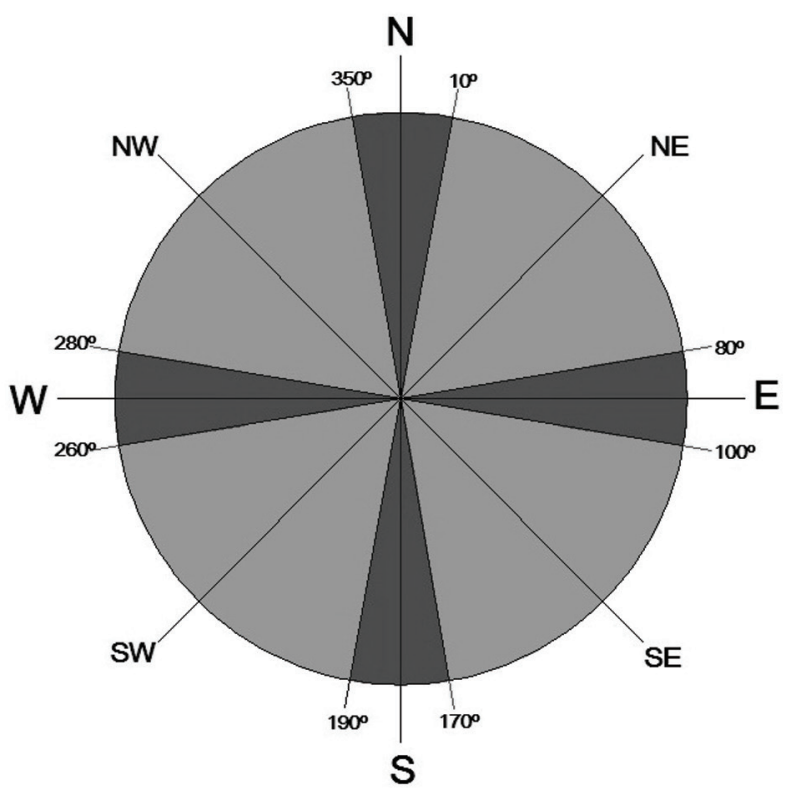

Figura 4. Diagrama de rosetas utilizado neste trabalho. 


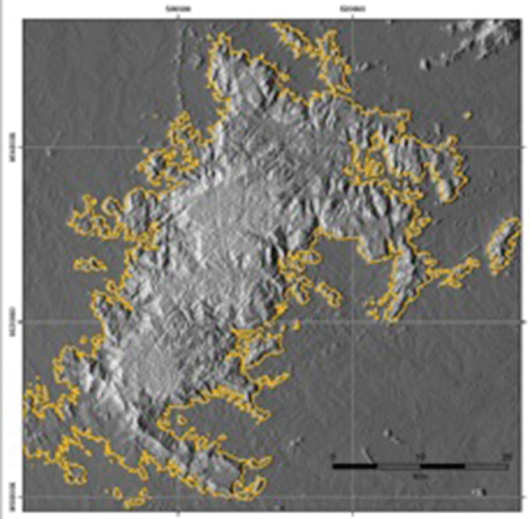

SRTM - Filtro Direcional $0^{\circ} \mathrm{Az}$

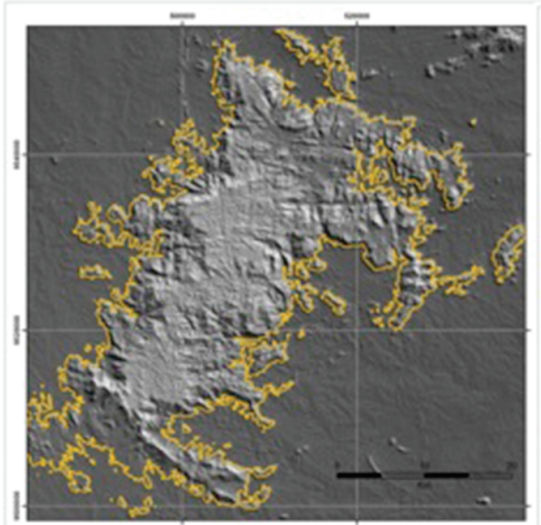

SRTM - Filtro Direcional $135^{\circ} \mathrm{Az}$

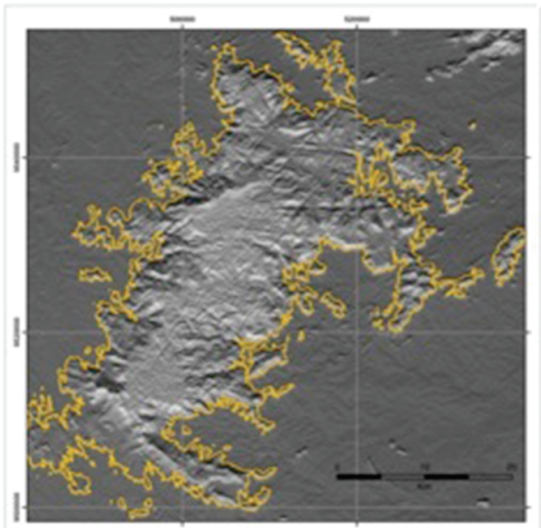

SRTM - Filtro Direcional $270^{\circ} \mathrm{Az}$

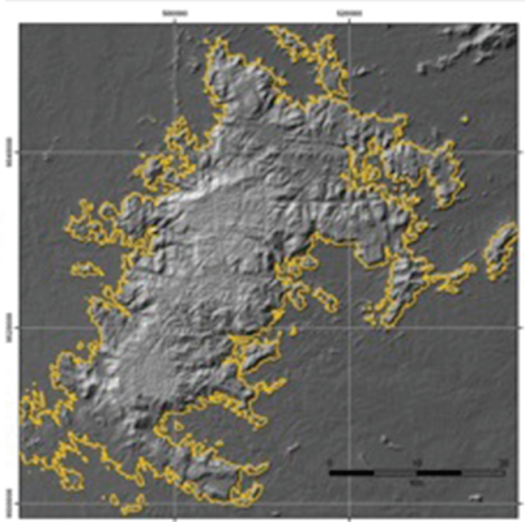

SRTM - Filtro Direcional $45^{\circ} \mathrm{Az}$

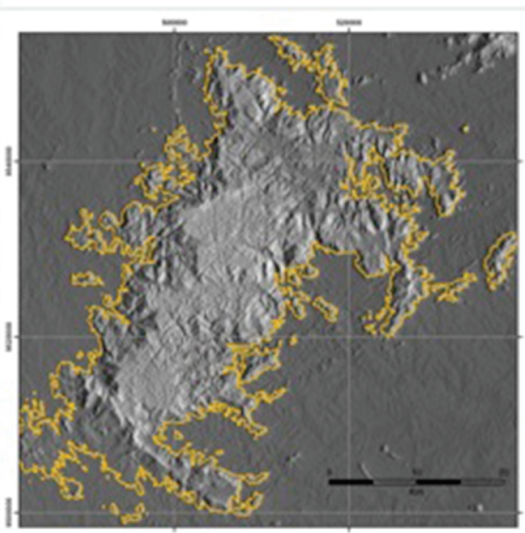

SRTM - Filtro Direcional $180^{\circ} \mathrm{Az}$

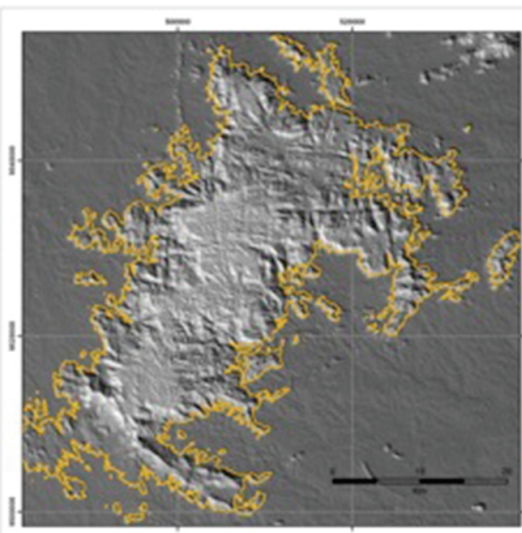

SRTM - Filtro Direcional $315^{\circ} \mathrm{Az}$

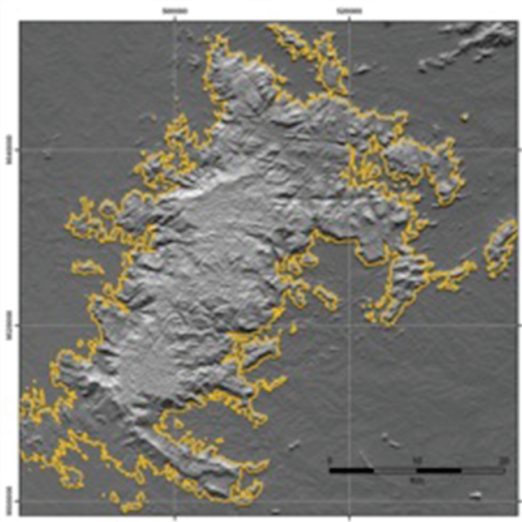

SRTM - Filtro Direcional $90^{\circ} \mathrm{AZ}$

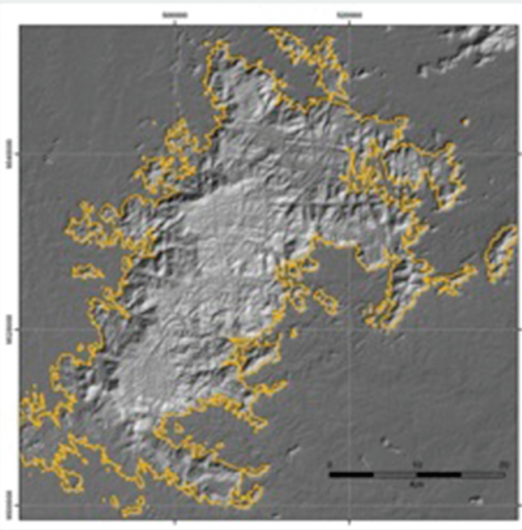

SRTM - Filtro Direcional $225^{\circ} \mathrm{Az}$

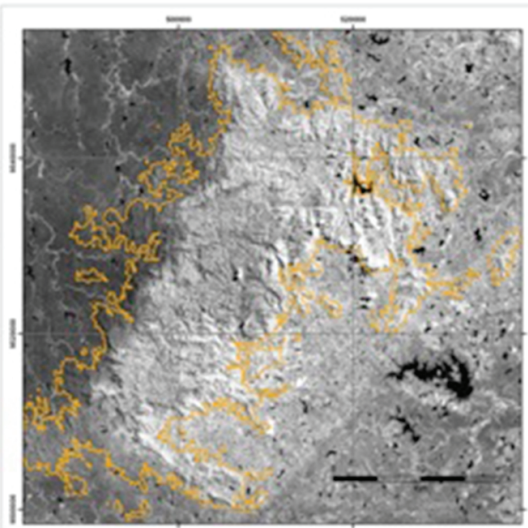

Landsat (Banda 4) - Filtro High-Pass tipo Kernel

Figura 5. Sequência de imagens SRTM e LANDSAT após aplicação de filtragens.

raster de saída, ou seja, fornece a concentração dos comprimentos dos lineamentos por unidade de área (Figuras 7 e 8 , respectivamente).

\section{Mapa de arcabouço estrutural regional}

Com a junção da pesquisa cartográfica prévia da região de estudo e com o uso das imagens SRTM e LANDSAT, pode-se obter um mapa geral das estruturais dúcteis e rúpteis regionais. Para tanto, foram utilizados os dados obtidos nos trabalhos de Torres (2004), Paes (2004) e Alves (2012), no mapa geológico da Folha Baturité SB.24 X-A-I (CPRM, 2012), além de levantamento de campo.

Sobre os mapas produzidos nos referidos trabalhos, procedeu-se, com a ajuda da interpretação de imagens da banda 04 do LANDSAT e das imagens SRTM, a vetorização de 
lineamentos dúcteis, como uma série de zonas de cisalhamento que ocorrem no setor leste da serra e que flexionam em sentido SW (Figura 9).

Este produto representa o resultado final da sinergia entre o uso de imagens ópticas e de radar na geração de lineamentos estruturais.

\section{DISCUSSÃO}

A interpretação das estruturas ressaltadas nas imagens aqui utilizadas permitiu reconhecer dois domínios estruturais distintos: um setor topograficamente mais alto da Serra de Baturité (maciço residual), onde predominam as estruturas rúpteis; e um entorno rebaixado (depressão sertaneja), onde as estruturas dúcteis são as feições dominantes.

No setor nordeste da serra destaca-se um conjunto penetrativo de estruturas orientadas $\mathrm{N}-\mathrm{S}$, responsável pelo entalhe de alguns vales perpendiculares ao Rio Pacoti e pela própria inflexão que esse faz em sentido norte, à altura da localidade de Areias. Dois densos feixes de lineamentos orientados no sentido E-W encontram-se associados a zonas de cisalhamento dúcteis transcorrentes mapeadas pelo Serviço Geológico do Brasil (CPRM, 2012) e

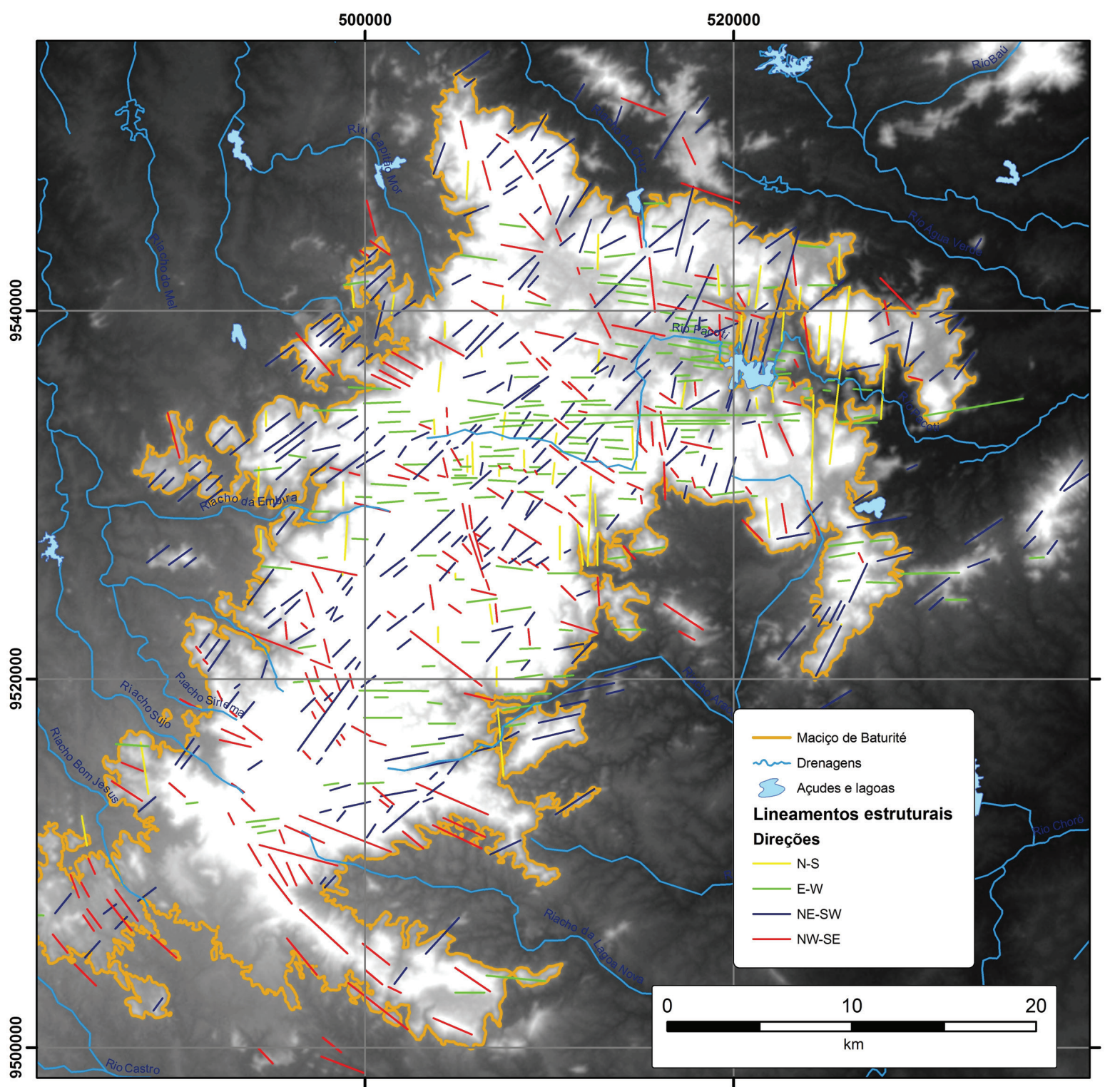

Figura 6. Mapa de direção de lineamentos. 


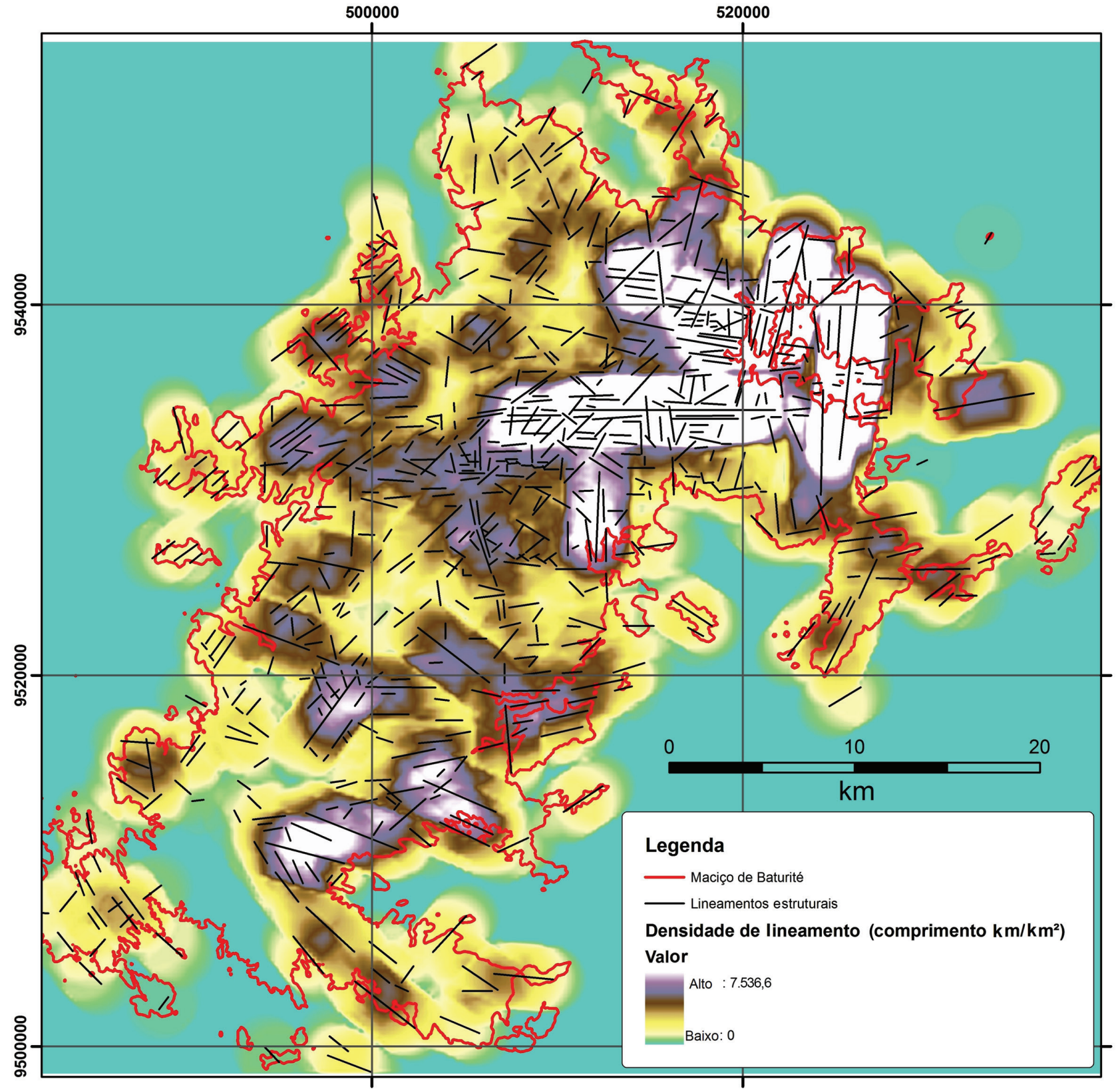

Figura 7. Densidade de lineamentos (população de lineamentos por km²).

por Torres (2004). A zona de cisalhamento mais ao sul é mais ampla, penetrativa e controla longo trecho do Rio Pacoti no setor em que ele atravessa a cidade homônima. Outra zona de cisalhamento está situada a cerca de $10 \mathrm{~km}$ ao norte da primeira e controla trecho do Riacho Salgado. Uma segunda inflexão ocorre pra leste, onde o Rio Pacoti deságua no Açude Acarape, e é controlada por outras estruturas lineares de sentido E-W com tendência a NW-SE.
No interior do maciço os lineamentos orientados NW-SE e NE-SW correspondem a fraturas, pequenas falhas e outras descontinuidades que se sobrepõem, por vezes a traços da foliação tectono-metamórfica, cujo controle geomorfológico é menos expressivo. Entretanto, a influência dos lineamento NE-SW e NW-SE é marcante nas bordas e limites externos com a Depressão Sertaneja.

Quanto ao mergulho das foliações e fraturas, as imagens de satélite não permitem a obtenção de dados em nível de 


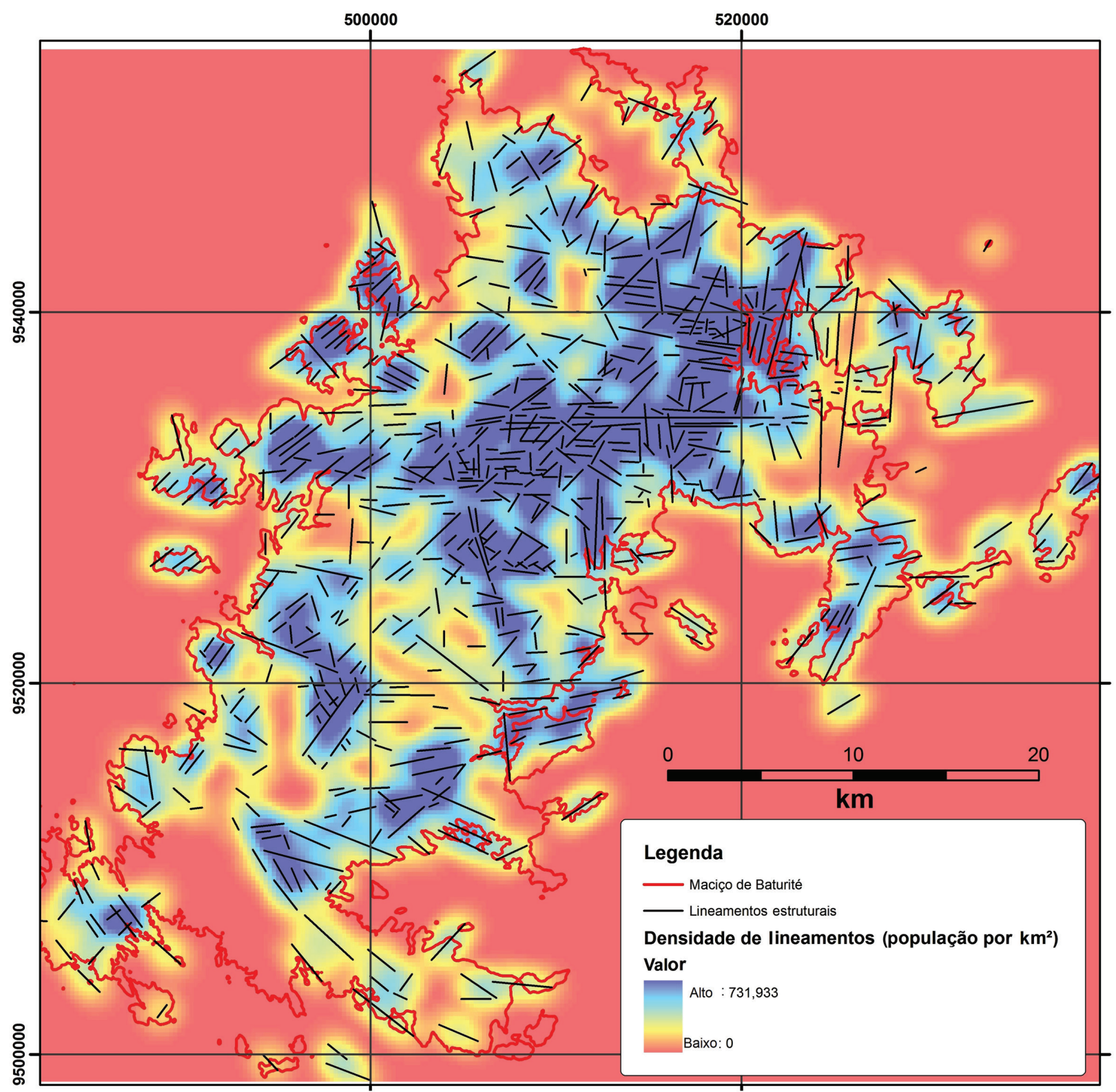

Figura 8. Densidade de lineamentos (comprimento dos lineamentos em km por km²).

detalhe. É preciso o levantamento de campo para atribuir às feições lineares extraídas com o tratamento das imagens de satélite, informações sobre direção e mergulho de camadas ou fraturas.

Na zona de cimeira da serra de Baturité, observou-se que o mergulho das foliações são mais verticalizadas quando próximas às zonas de cisalhamento $(\mathrm{ZC})$, tornando-se horizontalizadas a sub-horizontalizadas à medida que se distanciam das zonas de cisalhamento.

No leito do Rio Pacoti, próximo à sede municipal, a foliação apresenta orientação E-W e mergulhos entre $68^{\circ}$ e $80^{\circ}$ para norte (Figura 10A). Ao longo dos planos de foliação observa-se uma lineação de estiramento mineral sub-horizontal (N65/18) (Figura 10B), que somada às feições miloníticas e estruturas tipo budinagem sugerem movimentação direcional em zona de cisalhamento dúctil transcorrente (Figuras 10C, 10D e 10F). Feições similares são observadas mais a norte, cerca de $10 \mathrm{~km}$ acima do Rio Pacoti (Figuras $11 \mathrm{~A}$ a 11E). Referidas ZC de alto ângulo coincidem com a porção central de duas áreas de maior densidade de lineamentos em população e comprimento (Figuras 7 e 8 ).

Estruturas rúpteis mais novas representadas por fraturas e pequenas falhas se superpõem aos planos de foliação metamórfica, formando sistemas com orientação subparalela, 
transversal e em ângulo com sua orientação principal (Figuras $10 \mathrm{E}, 11 \mathrm{~B}, 11 \mathrm{E}$ e $11 \mathrm{~F})$.

Nas vertentes, as foliações assumem ângulos de mergulhos intermediários, muitas vezes em direção aos cortes de estrada, como o caso das estradas CE-065 e CE-228 que ligam a cidade de Pacoti, respectivamente, a Fortaleza e Campos Belos (BR-020). Os condicionantes geológicogeotécnicos de estabilidade de taludes na rodovia CE-065 (km 46 a 64,3) foram estudados por Alves (2012).
Nessas estradas, as foliações concentram-se no quadrante nordeste, variando, de modo geral, entre as direções norte e leste; e possuem mergulhos médios em torno de $35^{\circ}$ na direção das vertentes naturais e cortes de estrada, acentuando a propensão de movimentos translacionais e rupturas planares associados às fraturas orientadas transversalmente à foliação; e fenômenos de queda de blocos e tombamentos relacionados a fraturas subverticais, paralelas à face dos taludes (Figuras 12A e 12B).

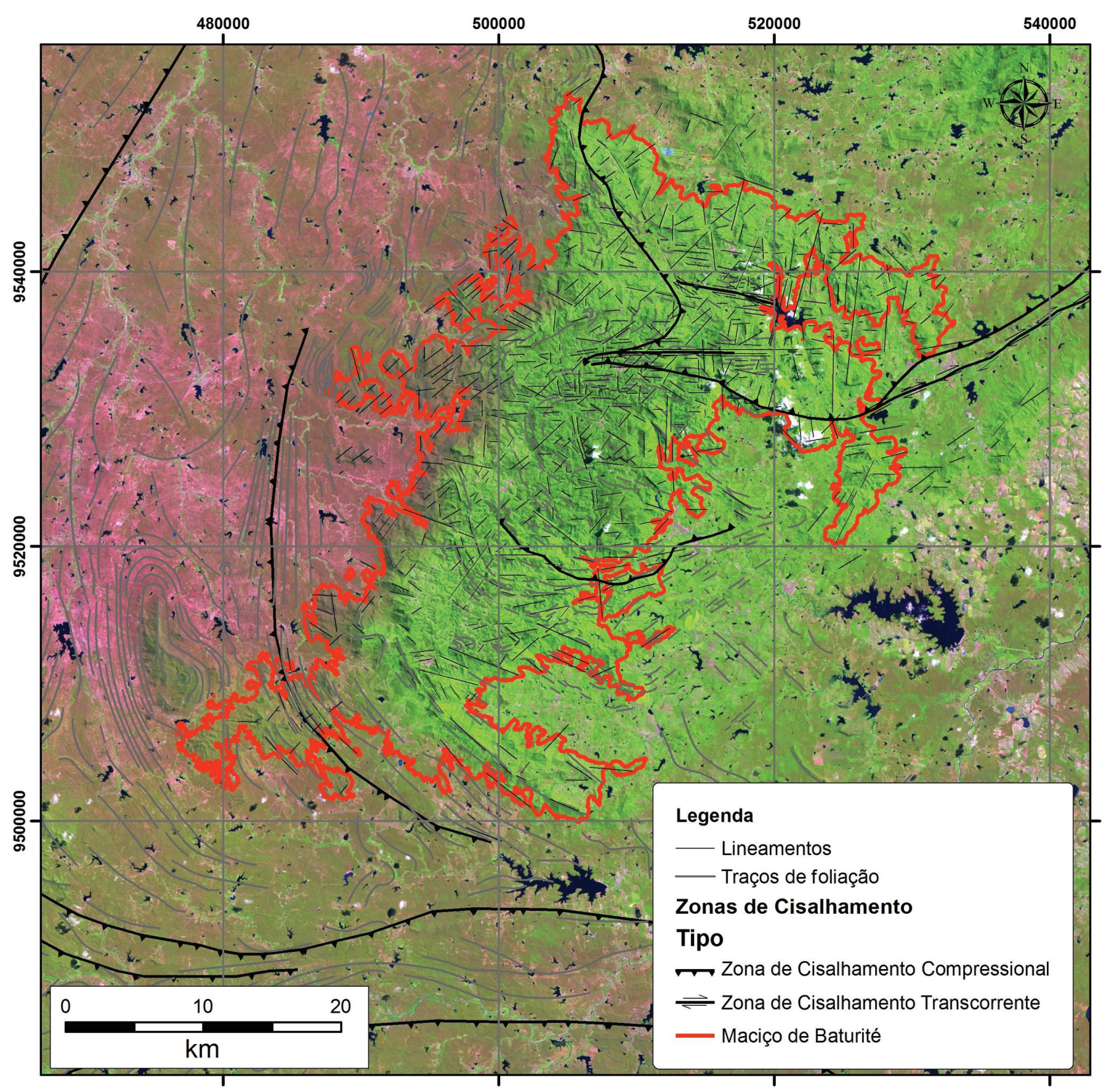

Figura 9. Arcabouço estrutural regional. 

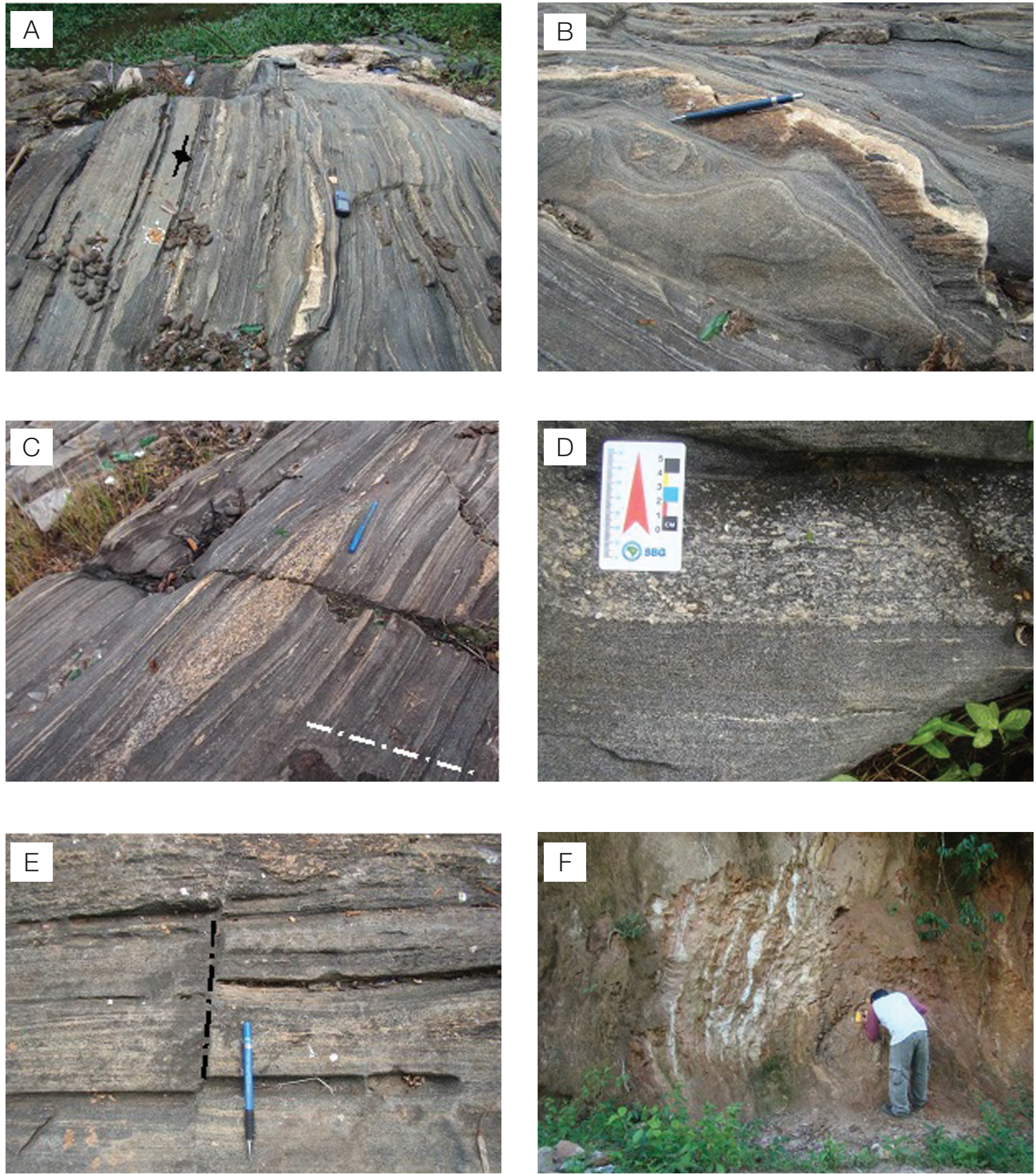

Figura 10. (A) Bandamento gnáissico subvertical (N90E 68-80/NW) em zona de cisalhamento dúctil no leito do Rio Pacoti, abaixo da ponte sobre o rio na saída de Pacoti para Palmácia (coord. 509479/9533001-SUTM24 /WGS84); (B) lineação de estiramento mineral (N65/18) sobre plano de foliação subvertical em zona de cisalhamento dúctil de alto ângulo; (C) boudinagem em banda quartzo-feldspática seccionada por fratura norte-sul subvertical; (D) detalhe de banda quartzo-fedspática de composição granodiorítica milonitizada, contendo porfiroclástos de feldspato e cristais de quartzo estirados; (E) microfalhamentos deslocando bandas quartzo-feldspáticas e biotíticas nos gnaisses situados no leito do Rio Pacoti; (F) granada biotita gnaisses em ZC dúctil de alto ângulo a norte do Rio Pacoti, em corte de estrada que liga Pacoti a localidade de Ouro (coord. 511389/9534435-SUTM24/WGS84). 

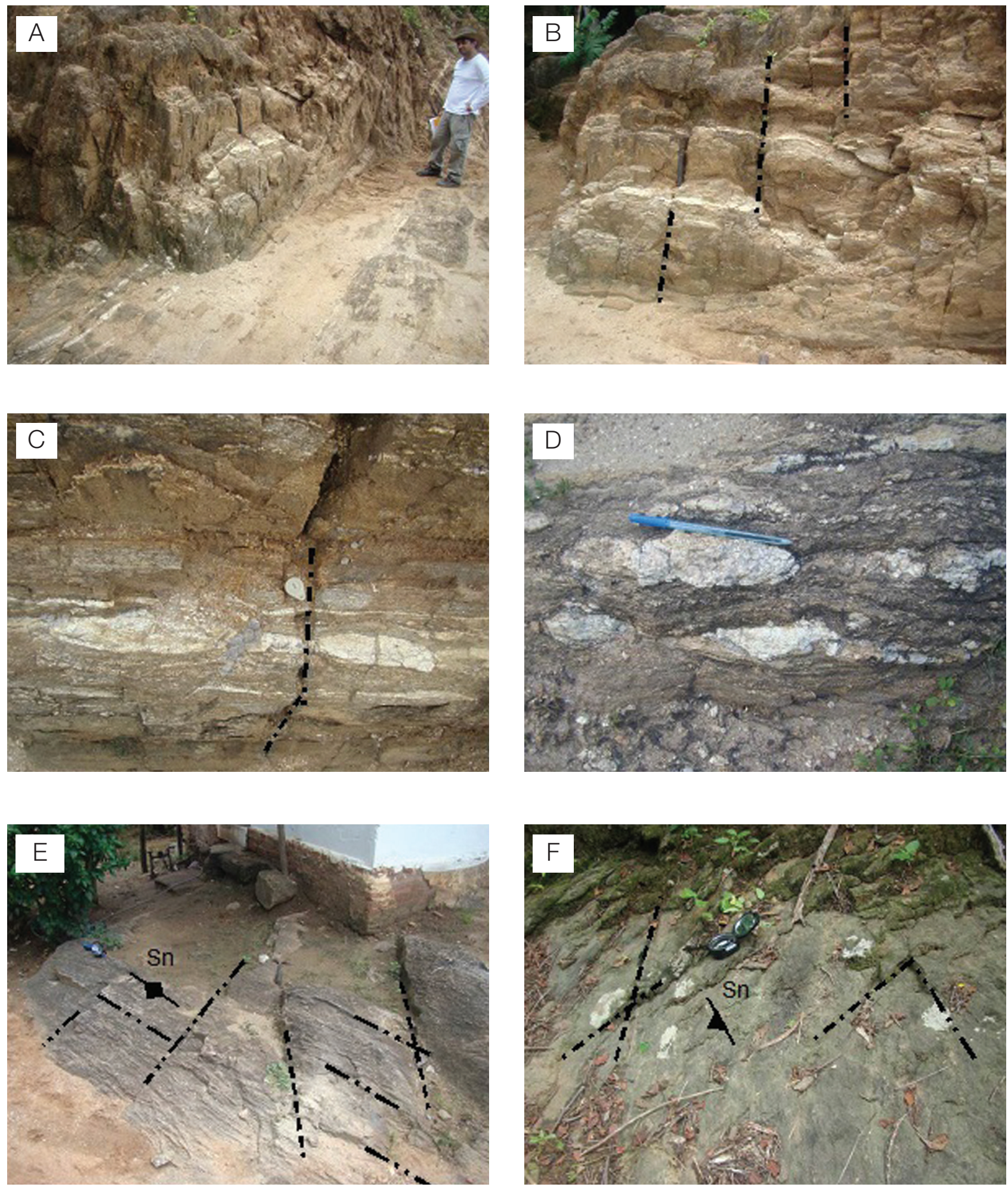

Figura 11. (A) Biotita gnaisses deformados em zona de cisalhamento dúctil vertical, situada a cerca de $10 \mathrm{~km}$ ao norte do Rio Pacoti, próximo à localidade de Volta do Rio (coord. 514368/95338930- SUTM24/WGS84); (B) detalhe de sistema de fraturas N-S, transversais ao bandamento gnaissico verticalizado; (C e D) bandas quartzo-feldspáticas e neossomas lenticularizados e boudinados em zona de cisalhamento dúctil de alto ângulo; (E e F) sistemas de fraturas rúpteis subparalelas, transversais e, em ângulo, com a foliação milonítica presente nos biotita gnaisses e xistos da Unidade Independência (coord. 514391/9538619-SUTM24/WGS84). 

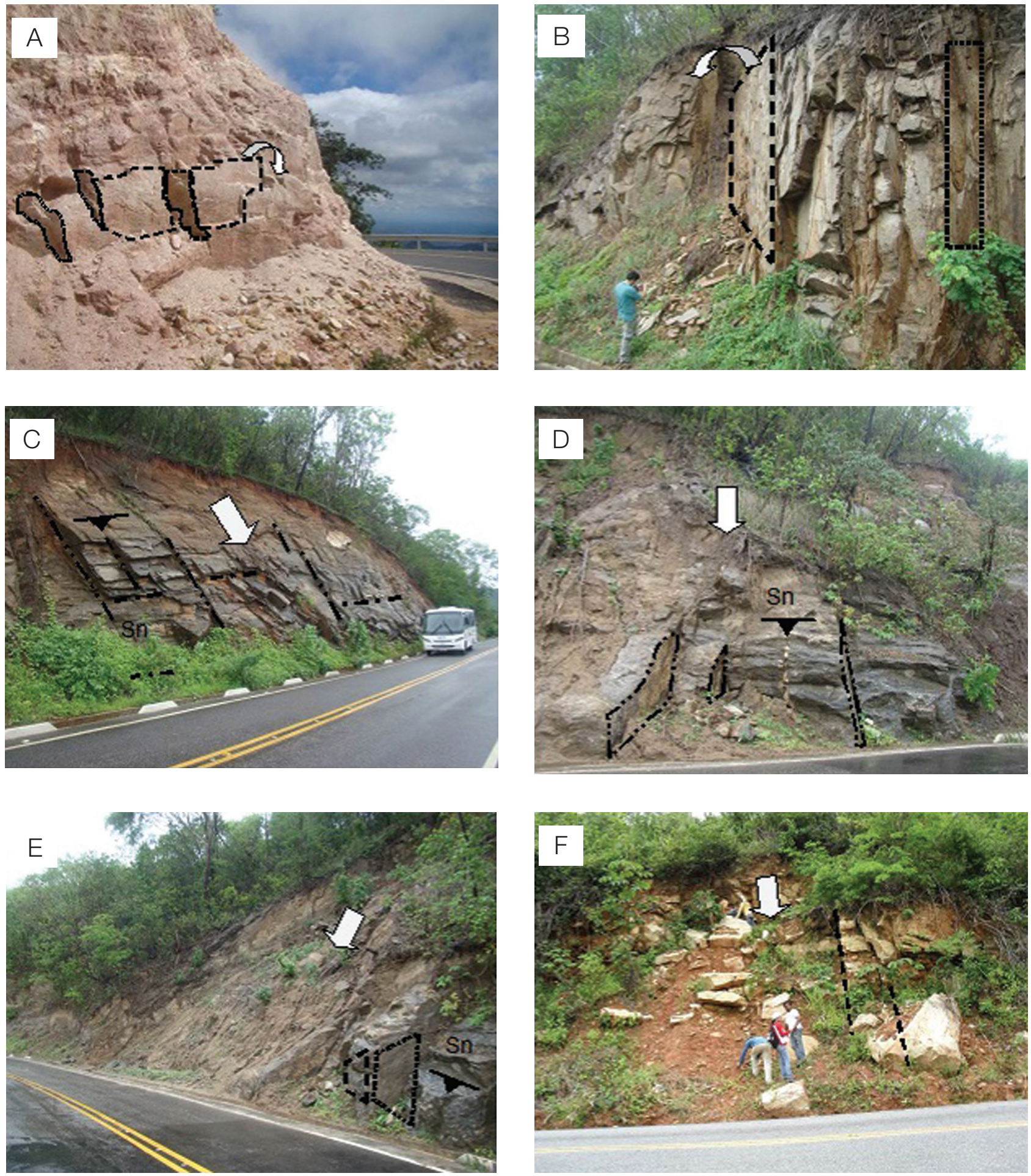

Figura 12. (A) Talude na rodovia CE-228 com risco de queda de blocos e tombamentos associados a fraturas subverticais em quartzitos da Unidade Independência (coord. 504142/9535330 SUTM24/WGS84); (B) queda de blocos e tombamentos controlados por fraturas subverticais orientadas N50W em granodiorito (coord. 522861/9544099 SUTM24/ WGS84); (C) planos de foliação e fraturas transversais, condicionando rupturas planares em talude localizado na CE-065 (coord. 523060/9544756 SUTM24/WGS84); (D e E) planos de foliação e fraturas transversais, condicionando rupturas planares em talude localizado na CE-065 (coord. 523060/9544756 SUTM24/WGS84); (F) escorregamento translacional em quartzitos condicionado por planos de foliação e fraturas transversais orientadas na estrada CE-065 entre Baturité e Guaramiranga (coord. 510564/9524425 - SUTM24/WGS84). 
Nessa área, a maioria das descontinuidades estruturais pode ser classificada como juntas, e, por conseguinte, não apresenta movimentação alguma, o que limita a disponibilidade de informações sobre a tectônica nesse setor. Essas fraturas se apresentam espaçadas e preenchidas de quartzo, feldspato ou material pegmatítico, direção preferencial E-W e mergulho médio de $75^{\circ}$ (Alves, 2012).

Há também algumas fraturas penetrando a foliação, promovendo o fluxo de água entre as camadas em setores em que já ocorreram deslizamentos. Isso facilita a liberação de blocos e aumenta a instabilidade do talude.

\section{CONSIDERAÇÕES FINAIS}

O uso concomitante de imagens radiométricas e ópticas (SRTM e LANDSAT, respectivamente) no estudo das feições lineares se mostrara um importante recurso na obtenção de dados estruturais e na diferenciação entre domínios estruturais dúcteis e rúpteis. A aplicação dos filtros direcionais na imagem SRTM permitiu a vetorização de mais de 700 lineamentos na região de estudo, a maioria interpretada como falhas e fraturas de natureza rúptil. Por outro lado, a aplicação do filtro high-pass na banda 04 da imagem LANDSAT permitiu, além da interpretação de feições claramente rúpteis, o mapeamento de foliações e estruturas de natureza dúctil.

Constata-se que a maior parte das estruturas lineares segue o trend regional no sentido NE-SW, seguido estatisticamente pelas estruturas NW-SE, ambas representadas por fraturas, pequenas falhas e outras descontinuidades rúpteis que se sobrepõem a traços da foliação, cujo controle geomorfológico é menos expressivo. A maior densidade de estruturas de sentido NW-SE ocorre no setor sul, nas bordas e limites externos da serra com a Depressão Sertaneja, geralmente associada aos planos curvos de foliação, adjacentes a zonas de cavalgamento de baixo ângulo.

As feições no sentido E-W possuem, também, grande representação estatística em termos de orientação espacial e constituem a maior densidade de lineamentos, tanto em número quanto em comprimento por unidade de área. Essas feições são materializadas em campo por duas importantes zonas de cisalhamento.

A inferior controla drenagens importantes, como o Rio Pacoti, e delineia o contato tectônico entre embasamento (Complexo Tamboril-Santa Quitéria) e cobertura (Complexo Ceará). Nesse caso, o controle principal é dúctil, combinando traços de foliações de baixo ângulo (empurrões) com alto ângulo (transcorrências) ao longo de uma faixa de cerca de $10 \mathrm{~km}$ de extensão por $2 \mathrm{~km}$ de largura. Um segundo feixe de lineamentos E-W com pequena inflexão para noroeste situa-se mais a norte e coincide com outra zona de cisalhamento dúctil de alto ângulo que controla a desembocadura do Rio Pacoti no Açude Acarape. Em ambos os casos a foliação milonítica é seccionada por fraturas predominantemente $\mathrm{N}-\mathrm{S}$ formando pequenas rupturas de relevo e trechos encachoeirados.

Para fins de mapeamento de risco geológico associado a movimentos de massa, os resultados aqui obtidos são de grande valia, uma vez que, como já mencionado, as orientações espaciais e mergulhos dos planos de falhas, fraturas e foliações são condicionantes de primeira ordem para a sua ocorrência, e o mapeamento dessas estruturas é um dos passos iniciais para a geração de cartas geotécnicas e de suscetibilidade a movimentos de massa e ruptura de taludes.

\section{REFERÊNCIAS}

Alves, L. E. F. (2012). Investigação dos condicionantes geológico-geotécnicos de estabilidade de taludes entre os quilômetros 46 e 64,3 da Rodovia CE-065 em Palmácia-CE. Relatório (Graduação). Fortaleza: Departamento de Geologia - UFC.

Bastos, F. H. (2012). Classificação dos movimentos de massa no Maciço de Baturité (CE) e contribuições para estratégias de planejamento ambiental. Tese (Doutorado). Fortaleza: Departamento de Geografia - UFC.

Bétard, F., Peulvast, J. P., Sales, V. C. (2007). Caracterização morfopedológica de uma serra úmida no semi-árido do nordeste brasileiro: o caso do Maciço de Baturité-CE. Mercator - Revista de Geografia da UFC, 6(12), 107-126.

Cavalcante, J. C., Vasconcelos, A. M., Gomes, F. E. M. (2003). Mapa Geológico do Estado de Ceará. Escala 1: 500.000. Fortaleza: Companhia de Pesquisa de Recursos Minerais/CPRM.

Chaves, J. M., Sano, E. E., Edi, M. G., Silva, A. B., Meneses, P. R. (2003). Sinergismo entre dados ópticos e de radar no estudo geológico da região de Bezerra-Cabeceiras, Goiás. Revista Brasileira de Geociências, 33(Suppl. 2), 137-146. Acesso em 28 de novembro de 2011, <http:// sbgeo.org.br/pub_sbg/rbg/vol33_down/3302suplemento/ sr-18.pdf $>$.

CPRM - Companhia de Pesquisa de Recursos Minerais. (2012). Mapa Geológico da Folha SB.24 - X-A-I Baturité. Escala 1:100.000, Fortaleza: CPRM.

Gerscovich, D. M. S. (2009). Estabilidade de taludes. Acesso em 23 de setembro de 2011, <http://www.defesacivil.es.gov.br/ files/meta/9c79332b-f0d2-4891-8f9c-b26d981b2258/11aab571c042-43da-8c5d-328853b1f190/91.pdf >. 
Klein, M. A. (1998). Integração de imagens TM e aerogeofisicas para análises lito-estruturais de uma porção da zona de cisalhamento transcorrente dorsal de Cangunçu, Região de Quitéria - Várzea do Capivarita, RS. Dissertação (Mestrado). Porto Alegre: Centro Estadual de Pesquisas em Sensoriamento Remoto e Meteorologia - UFRGS

Paes, K. A. D. (2004). Análise da vulnerabilidade à erosão na bacia hidrográfica do Rio Pacoti (Serra de Baturité). Dissertação (Mestrado). Fortaleza: Departamento de Geologia - UFC.

Silva, A. F. M. (2007). Análise da suscetibilidade à erosão dos solos na microbacia do Riacho dos Barros, Município de Aratuba - Ceará. Dissertação (Mestrado). Fortaleza: Departamento de Geologia - UFC.

Souza, M. J. N. (2000). Bases naturais e esboço do zoneamento geoambiental do estado do Ceará. In: L. C. Lima, J. O. Morais, M. J. N. Souza (Eds.), Compartimentação
Territorial e Gestão Regional do Ceará (05-102). Fortaleza: FUNECE.

Souza, M. J. N., Lima, F. A. M., Paiva, J. B. (1979). Compartimentação topográfica do estado do Ceará. Ciências Agronômicas UFC, 9(1-2), 77-86.

Souza, M. J. N., Oliveira, V. P. V. (2006). Os enclaves úmidos e sub-úmidos do semi-árido do nordeste brasileiro. Mercator - Revista de Geografia da UFC, 9, 85-102.

Torres, P. F. M. (2004). Aspectos geológicos e geocronológicos da região de Redenção (CE) e adjacências - contexto regional e evolutivo: Sequência Acarape e Suite Pacatuba. Dissertação (Mestrado). Fortaleza: Departamento de Geologia - UFC.

Torres, P. F. M., Parente, C. V., Dantas, E. L., Arthaud, M. H., Fuck, R. A., Neto, J. A. N., Castro, D. L. (2006). Seqüência metavulcano-sedimentar Acarape, CE: aspectos geológicos e isotópicos $\mathrm{Sm} / \mathrm{Nd}$. Revista de Geologia da UFC, 2, 163-176. 